ORIGINAL ARTICLE

\title{
Restoration of cardiopulmonary function with $21 \%$ versus $100 \%$ oxygen after hypoxaemia in newborn pigs
}

\author{
D Fugelseth, W B Børke, K Lenes, I Matthews, O D Saugstad, E Thaulow
}

Arch Dis Child Fetal Neonatal Ed 2005;90:F229-F234. doi: 10.1136/adc.2004.056986

See end of article for authors' affiliations

....................

Correspondence to: Dr Fugelseth, Department of Paediatrics, Ullevål University Hospital, NO-0407 Oslo, Norway; drfu@uus.no

Accepted

8 November 2004
Objective: To assess the consequences of hypoxaemia and resuscitation with room air versus $100 \% \mathrm{O}_{2}$ on cardiac troponin I (cTnl), cardiac output (CO), and pulmonary artery pressure (PAP) in newborn pigs. Design: Twenty anaesthetised pigs (12-36 hours; $1.7-2.7 \mathrm{~kg})$ were subjected to hypoxaemia by ventilation with $8 \% \mathrm{O}_{2}$. When mean arterial blood pressure fell to $15 \mathrm{~mm} \mathrm{Hg}$, or arterial base excess was $\leqslant-20 \mathrm{mmol} / \mathrm{l}$, resuscitation was performed with $21 \%(\mathrm{n}=10)$ or $100 \%(\mathrm{n}=10) \mathrm{O}_{2}$ for 30 minutes, then ventilation with $21 \% \mathrm{O}_{2}$ for 120 minutes. Blood was analysed for cTnl. Ultrasound examinations of $\mathrm{CO}$ and PAP (estimated from tricuspid regurgitation velocity (TR-Vmax)) were performed at baseline, during hypoxia, and at the start of and during reoxygenation.

Results: $c T n l$ increased from baseline to the end point $(p<0.001)$, confirming a serious myocardial injury, with no differences between the $21 \%$ and $100 \% \mathrm{O}_{2}$ group ( $p=0.12$ ). TR-Vmax increased during the insult and returned towards baseline values during reoxygenation, with no differences between the groups $(p=$ 0.11 ) or between $c T n l$ concentrations $(p=0.31)$. An inverse relation was found between increasing age and TR-Vmax during hypoxaemia $(p=0.034)$. CO per $\mathrm{kg}$ body weight increased during the early phase of hypoxaemia $(p<0.001)$, then decreased. Changes in $\mathrm{CO}$ per $\mathrm{kg}$ were mainly due to changes in heart rate, with no differences between the groups during reoxygenation $(p=0.298$ ).

Conclusion: Hypoxaemia affects the myocardium and PAP. During this limited period of observation, reoxygenation with $100 \% \mathrm{O}_{2}$ showed no benefits compared with $21 \% \mathrm{O}_{2}$ in normalising myocardial function and PAP. The important issue may be resuscitation and reoxygenation without hyperoxygenation.
$M$ yocardial dysfunction, hypotension, and increased pulmonary vascular resistance are well known consequences of hypoxic-ischaemic insults in neonates, ${ }^{1}$ with a relation between low alveolar oxygen tension and increased pulmonary vascular resistance. ${ }^{2}$ In contrast with chronic hypoxia, the effects are reversible with reoxygenation after insults of short duration. ${ }^{3}$

Cardiac troponin I (cTnI) is a regulatory contractile protein. The troponin complex has three subunits in the thin filament of the muscle myofibrils, where cTnI is the actomyosin ATPase inhibiting subunit. It has been shown to be a specific and sensitive marker for myocardial damage in both human infants ${ }^{4}$ and an experimental model of newborn asphyxiated pigs. $^{5}$

In modern neonatal intensive care units, sick neonates are monitored with continuous electrocardiography, invasive blood pressure, respiratory rate, and saturation of oxygen in arterial blood. Doppler echocardiography is a useful noninvasive diagnostic method of assessing ventricular filling, ventricular function, and, more specifically, ventricular output and pulmonary artery pressure (PAP). Echocardiography may be useful in monitoring newborn animals as well. ${ }^{6-8}$

Birth asphyxia is a worldwide problem leading to high morbidity and mortality. ${ }^{9}$ Treatment strategies in neonatal resuscitation are mainly based on tradition and, to a lesser extent, on evidence based medicine. ${ }^{10}$ The aim of successful resuscitation is to prevent both neonatal death and adverse long term neurodevelopmental outcome associated with birth asphyxia. Oxygen delivery to organs must be sufficient to provide adequate oxygen consumption and prevent tissue acidosis. It is also important to prevent further tissue damage caused by reoxygenation and oxygen toxicity injury. ${ }^{11}$

There is an ongoing debate on the optimal concentration of oxygen for neonatal resuscitation. International Guidelines for Neonatal Resuscitation in 2000 recommended resuscitation of the newborn infant with $100 \%$ oxygen. ${ }^{12}$ Several animal and also human studies have suggested that room air is as effective as, or may be even better than, 100\% oxygen in resuscitation. ${ }^{11}{ }^{13-18}$

The aim of this study was to assess the consequences of hypoxaemia and reoxygenation with $21 \%$ and $100 \%$ oxygen on cardiac output (CO) and PAP by Doppler echocardiography and on serum cTnI in a newborn pig model.

\section{METHODS \\ Approval}

The Norwegian Animal Experimental Board approved the experimental protocol. The animals were cared for and handled in accordance with the European guidelines for use of experimental animals.

\section{Animal preparation}

Of 28 anaesthetised and tracheotomised Landrace pigs, 20 (12-36 hours old, weight $1.7-2.7 \mathrm{~kg}$ ) were included in the study. Three pigs were used as sham animals and treated as the experimental animals except for the hypoxaemic insult and reoxygenation. Five pigs had to be excluded, two because of diarrhoea/sepsis, and three died from complications from the hypoxic-ischaemic insult, such as serious bradyarrhythmia.

General anaesthesia was induced with halothane and discontinued when venous access was achieved, usually within two minutes. After induction, a bolus dose of $10 \mathrm{mg} /$ $\mathrm{kg}$ pentobarbital, $10-30 \mu \mathrm{g} / \mathrm{kg}$ fentanyl, and $1 \mathrm{mg} / \mathrm{kg}$ midazolam was given. When tracheotomy had been performed, anaesthesia was given as a continuous infusion of $50 \mathrm{mg}$ / $\mathrm{kg} / \mathrm{h}$ fentanyl and $0.25 \mathrm{mg} / \mathrm{kg} / \mathrm{h}$ midazolam.

Abbreviations: CO, cardiac output; cTnl, cardiac troponin I; LVP, left ventricular pressure; PAP, pulmonary artery pressure; TR-Vmax, peak tricuspid regurgitation velocity 
Table 1 Baseline values

\begin{tabular}{|c|c|c|c|}
\hline & Sham $(n=3)$ & $21 \%(n=10)$ & $100 \%(n=10)$ \\
\hline Age (hours) & 33.7 (3.2) & $26.7(8.2)$ & $28.0(8.7)$ \\
\hline Body weight (kg) & $2.33(0.45)$ & $2.07(0.29)$ & $2.05(0.37)$ \\
\hline Haemoglobin (g/l) & $6.8(1.4)$ & $6.9(0.3)$ & $6.9(0.4)$ \\
\hline Calcium (g/l) & $1.44(0.04)$ & $1.36(0.02)$ & $1.34(0.12)$ \\
\hline $\mathrm{pH}$ & $7.47(0.05)$ & $7.49(0.02)$ & $7.44(0.02)$ \\
\hline Base excess (mmol/l) & $5.9(1.2)$ & $5.28(1.3)$ & $2.54(0.9)$ \\
\hline Heart rate (beats/min) & $132(9)$ & $152(9)$ & $165(12)$ \\
\hline Systolic BP (mm Hg) & $66(5)$ & $68(5)$ & $66(5)$ \\
\hline Diastolic BP (mm Hg) & $51(5)$ & $53(4)$ & $53(5)$ \\
\hline
\end{tabular}

Mechanical ventilation was performed with a pressure controlled ventilator (Babylog 8000+; Drägerwerk, Lübeck, Germany). Normoventilation $\left(\mathrm{PaCO}_{2} 4.5-6.0 \mathrm{kPa}\right)$ with tidal volume $10-15 \mathrm{ml} / \mathrm{kg}$ was achieved by adjusting peak inspiratory pressure or ventilatory rate. The inspiratory time of 0.4 second and positive end expiratory pressure of $4 \mathrm{~cm} \mathrm{H}_{2} \mathrm{O}$ were kept constant throughout the experiment. Inspired fraction of $\mathrm{O}_{2}$ and end tidal $\mathrm{CO}_{2}$ were continuously monitored $\left(\mathrm{CO}_{2} \mathrm{SMO}\right.$; Novametrix, Wallingford, Connecticut, USA).

Rectal temperature was maintained between 38 and $40^{\circ} \mathrm{C}$ with a heating blanket and a radiant heating lamp (normal pig temperature $38.5-39.5^{\circ} \mathrm{C}$ ).

Arterial and venous catheters were inserted into the right femoral artery and left external jugular vein (polyethylene catheters Portex PE-50; Portex Ltd, Hythe, Kent, UK) for arterial blood pressure monitoring, blood sampling, and fluid infusions. Continuous intravenous infusion with Salidex ( $35 \mathrm{mg} / \mathrm{ml}$ glucose, $50 \mathrm{mmol} / \mathrm{ml} \mathrm{NaCl}$ ) was given, and blood glucose was kept in the range $2-10 \mathrm{mmol} / \mathrm{l}$.

Guided by ultrasound, a $2 \mathrm{~F}$ micro manometer-tipped catheter (MPC-500, Millar catheter; Millar Instruments, Houston, Texas, USA) was inserted from the left carotid artery into the left ventricle for continuous monitoring of left ventricular pressure (LVP). The electrocardiogram was continuously monitored.

\section{Experimental protocol}

The animals were stabilised for one hour after surgery. Hypoxaemia was achieved by ventilation with a gas mixture of $8 \% \mathrm{O}_{2}$ in $\mathrm{N}_{2}$ (AGA, Oslo, Norway) until either mean arterial blood pressure reached $15 \mathrm{~mm} \mathrm{Hg}$ or base excess was $\leqslant-20 \mathrm{mmol} / \mathrm{l}$. Before resuscitation, the pigs were block randomised into two groups. Resuscitation was performed with either $21 \%$ or $100 \% \mathrm{O}_{2}$ for 30 minutes. Then the pigs were ventilated with room air for another 120 minutes. At the end of the experiment, the pigs were given an overdose of $150 \mathrm{mg} / \mathrm{kg}$ pentobarbital intravenously. ${ }^{5}$

\section{Blood samples}

Blood gases corrected for the pig's temperature were analysed after surgery, at baseline (HO), regularly through hypoxaemia, at the start and 10, 20, 30, and 120 minutes of reoxygenation, and at the end of the experiment. Haemoglobin was measured at baseline. Blood sampling for analysis of cTnI was collected at baseline and at the end of the study, centrifuged, and kept at $-70^{\circ} \mathrm{C}$ until analysis with an AIO Immunoanalyzer (Turku, Finland).

\section{Ultrasound examinations}

A Vivid 7 ultrasound scanner (GE VingMed Ultrasound, Horten, Norway) with an integrated program for quantitative analysis for humans and combined tissue imaging, and Doppler transducer (10S) with a range of frequencies from 4.0 to $10.0 \mathrm{MHz}$, was used. The analyses were mainly performed with the factory default of $8.9 \mathrm{MHz}$.

Two investigators (DF, KL), one handling the probe and one dealing with the ultrasound equipment, performed the ultrasound examinations. The data were sampled when both agreed that the imaging quality was optimal. The recordings were stored on black and white paper prints as well as CDROM and MO discs for further analysis.

The ultrasonographic studies were performed after anaesthesia and surgical instrumentation, at baseline (H0), 30 minutes after the start of hypoxia ( $\mathrm{H} 30)$, at the start of reoxygenation (R0), and at 30, 90, and 150 minutes of reoxygenation ( $\mathrm{R} 30, \mathrm{R} 90$, and $\mathrm{R} 150)$. With the pigs lying in a right lateral, half supine position, the first examination was performed to exclude congenital heart defects and persistent ductus arteriosus, to measure the aortic valve diameter, and to guide the insertion of the Millar catheter. The diameter of the aortic valve was measured as a leaflet separation from a parasternal long axis view from the inner edge of the hinge points of the aortic valve. This diameter was used for all calculations of $\mathrm{CO}$ to limit calculation errors due to measurement inaccuracy.

Further investigations were performed with pigs lying in a left lateral, half supine position. The peak tricuspid

Table 2 Values at end of insult (RO)

\begin{tabular}{llll}
\hline & Sham & $21 \%$ & $100 \%$ \\
\hline Hypoxaemia time (min) & - & $67.1(2)$ & $59.6(2)$ \\
$\mathrm{pH}$ & $7.48(0.02)$ & $7.08(0.01)$ & $7.10(0.02)$ \\
Base excess (mmol/l) & $3.83(1.76)$ & $-21.07(0.57)$ & $-20.70(0.70)$ \\
Heart rate (beats $/ \mathrm{min})$ & $128(8)$ & $174(21)$ & $172(18)$ \\
Systolic BP (mm Hg) & $66(4)$ & $37(6)$ & $26(3)$ \\
Diastolic BP (mm Hg) & $49(7)$ & $31(6)$ & $21(2)$ \\
\hline Values are mean (SD). Hypoxaemia was induced in all the experimental animals. They were then randomised to \\
one of two groups and resuscitated with either 21\% or 100\% $\mathrm{O}_{2}$.
\end{tabular}


Table 3 Measured and calculated cardiac variables

\begin{tabular}{|c|c|c|c|c|c|c|}
\hline & HO & H30 & RO & R30 & R90 & R150 \\
\hline \multicolumn{7}{|c|}{ Peak tricuspid regurgitation velocity $(\mathrm{m} / \mathrm{s})$} \\
\hline Sham & - & $2.46(0.04)$ & $2.30(0.03)$ & $2.28(0.05)$ & $2.39(0.07)$ & $2.35(0.05)$ \\
\hline $21 \%$ & $2.14(0.36)$ & $3.14(0.07)$ & $3.02(0.19)$ & $3.04(0.13)$ & $2.69(0.13)$ & $2.81(0.10)$ \\
\hline $100 \%$ & $2.62(0.18)$ & $2.95(0.08)$ & $2.96(0.20)$ & $2.90(0.20)$ & $2.69(0.08)$ & $2.88(0.13)$ \\
\hline \multicolumn{7}{|c|}{ Cardiac output (litres $/ \mathrm{min} / \mathrm{kg}$ ) } \\
\hline Sham & $0.340(0.04)$ & $0.331(0.09)$ & $0.302(0.06)$ & $0.329(0.08)$ & $0.304(0.03)$ & $0.305(0.04)$ \\
\hline $21 \%$ & $0.281(0.02)$ & $0.424(0.03)$ & $0.336(0.03)$ & $0.378(0.02)$ & $0.356(0.02)$ & $0.347(0.02)$ \\
\hline $100 \%$ & $0.371(0.04)$ & $0.417(0.03)$ & $0.513(0.06)$ & $0.415(0.04)$ & $0.401(0.04)$ & $0.403(0.05)$ \\
\hline \multicolumn{7}{|c|}{ Heart rate (beats $/ \mathrm{min}$ ) } \\
\hline Sham & $132(9)$ & $139(8)$ & $128(8)$ & $134(13)$ & $134(7)$ & $130(14)$ \\
\hline $21 \%$ & $152(9)$ & $202(12)$ & $174(21)$ & $183(12)$ & 178 (11) & $164(13)$ \\
\hline $100 \%$ & 165 (12) & $198(11)$ & $172(18)$ & $186(14)$ & 201 (14) & $179(11)$ \\
\hline \multicolumn{7}{|c|}{ Stroke volume $(\mathrm{ml} / \mathrm{kg})$} \\
\hline Sham & $2.44(0.43)$ & $2.40(0.89)$ & $2.38(0.61)$ & $2.44(0.63)$ & $2.30(0.38)$ & $2.42(0.41)$ \\
\hline $21 \%$ & $2.01(0.45)$ & $2.02(0.45)$ & $2.01(0.58)$ & $2.15(0.54)$ & $2.05(0.45)$ & $2.09(0.40)$ \\
\hline $100 \%$ & $2.40(0.54)$ & $2.07(0.37)$ & $2.47(0.69)$ & $2.17(0.48)$ & $2.03(0.50)$ & $2.29(0.88)$ \\
\hline
\end{tabular}

Values are mean (SEM). Hypoxaemia was induced in all the experimental animals. They were then randomised to one of two groups and resuscitated with either $21 \%$ or $100 \% \mathrm{O}_{2}$. Measurements were made at baseline $(\mathrm{HO}), 30$ minutes after the start of hypoxaemia $(\mathrm{H} 30)$, at the start of reoxygenation $(\mathrm{RO})$, and at 30,90 , and 150 minutes of reoxygenation (R30, R90, and R150).

regurgitation velocity (TR-Vmax, $\mathrm{m} / \mathrm{s}$ ) was sampled from the apical "four chamber view" to calculate the pressure gradient between the right ventricle and the right atrium $(\mathrm{mm} \mathrm{Hg})$ by using the inbuilt program in the ultrasound equipment applying the modified Bernoulli's equation. ${ }^{19}$ CO (litres/min) was calculated from stroke volume (velocity time integral across the aortic valve $\times$ valve area) $\times$ heart rate from the apical "five chamber view". Angle corrections were not used. All measurements used in the final calculation for each pig were the mean values, automatically calculated in the ultrasound scanner, from three to five consecutive beats regarded as good quality measurements. ${ }^{20}$

\section{Statistical analysis}

Statistical analysis was performed by SPSS11. Animal weight and age are given as mean (SD), and all other data are given as mean (SEM). Because of skewed distribution of CTnI, these variables were log transformed before analysis. For comparisons within two groups, the independent $t$ test, nonparametric test, or repeated measurements was used as appropriate. To study the linear relation between two variables, linear regression analysis was used. Area under

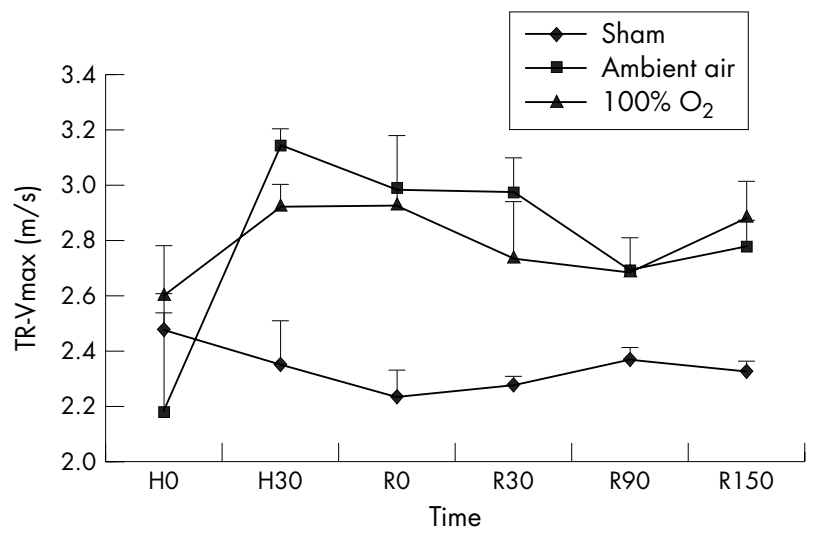

Figure 1 Peak tricuspid regurgitation velocity (TR-Vmax) in pigs subjected to hypoxaemia and resuscitated with either $21 \% \mathrm{O}_{2}$ lambient air) or $100 \% \mathrm{O}_{2}$. Measurements were made at baseline $(\mathrm{HO})$, 30 minutes after the start of hypoxaemia $(\mathrm{H} 30)$, at the start of reoxygenation (RO), and at 30,90 , and 150 minutes of reoxygenation (R30, R90, and R150). Values are mean (SEM) (sham, $\mathrm{n}=3$; ambient air, $\mathrm{n}=10 ; 100 \% \mathrm{O}_{2}, \mathrm{n}=10$ ). curve was used to obtain a summary measure of the variables. $\mathrm{p}<0.05$ was considered significant.

\section{RESULTS}

There were no differences between the two groups with regard to numbers of animals, sex, body weight, age, or cardiovascular and biochemical variables at baseline (table 1). The duration of the insult, mean arterial blood pressure, heart rate, $\mathrm{pH}$, and base excess at the end of the insult were similar in the two groups (table 2).

No pigs had any cardiac malformation, but four had patent ductus arteriosus. Two of them had an open duct from the first examination, whereas two reopened during the insult. All ductal shuntings were left-right, but the maximum systolic peak velocities were not measured because the angle errors were too large.

cTnI increased from baseline to end point $(0.05(0.003) v$ $0.34(0.100) \mu \mathrm{g} / \mathrm{l} ; \mathrm{p}<0.001)$ but with no differences between the $21 \%$ and $100 \% \mathrm{O}_{2}$ group $(\mathrm{p}=0.12)$. The analytical sensitivity of $\mathrm{CTnI}$ is $0.01 \mu \mathrm{g} / \mathrm{l}$, but the laboratory performing the analysis gave the lowest values as $<0.05 \mu \mathrm{g} / \mathrm{l}$. Of 23 pigs, 20 had values lower than $0.05 \mu \mathrm{g} / \mathrm{l}$. The sham piglets showed no change in cTnI $(<0.5 v<0.5 \mu \mathrm{g} / \mathrm{l})$.

Table 3 presents measured and calculated cardiac variables for the pigs. TR-Vmax increased in all pigs during the insult

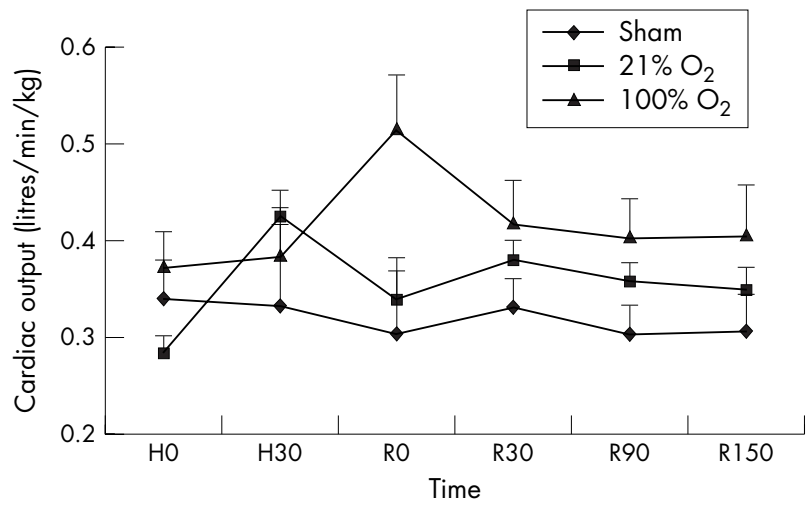

Figure 2 Cardiac output in pigs subjected to hypoxaemia and resuscitated with either $21 \%$ or $100 \% \mathrm{O}_{2}$. Measurements were made at baseline $(\mathrm{HO}), 30$ minutes after the start of hypoxaemia $(\mathrm{H} 30)$, at the start of reoxygenation (RO), and at 30,90, and 150 minutes of reoxygenation (R30, R90, and R150). Values are mean (SEM) (sham, $\mathrm{n}=3 ; 21 \% \mathrm{O}_{2}, \mathrm{n}=10 ; 100 \% \mathrm{O}_{2}, \mathrm{n}=10$ ). 


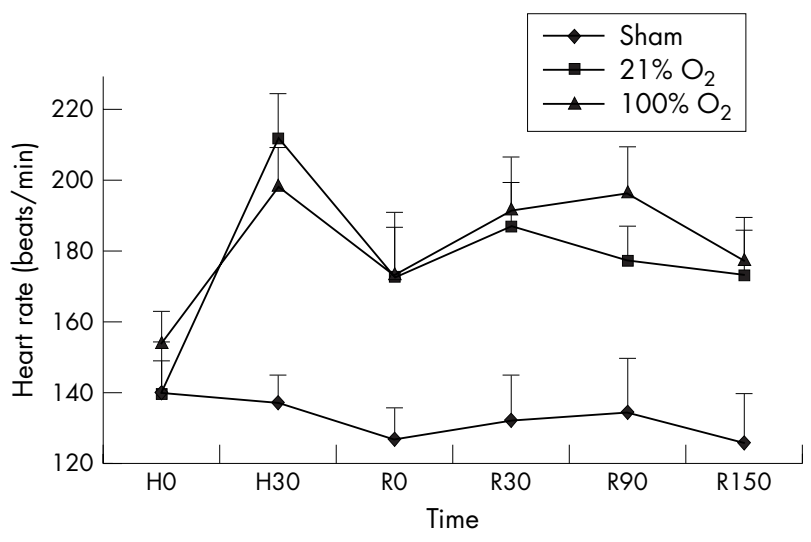

Figure 3 Heart rate in pigs subjected to hypoxaemia and resuscitated with either $21 \%$ or $100 \% \mathrm{O}_{2}$. Measurements were made at baseline $(\mathrm{HO}), 30$ minutes after the start of hypoxaemia $(\mathrm{H} 3 \mathrm{O})$, at the start of reoxygenation (RO), and at 30,90, and 150 minutes of reoxygenation (R30, R90, and R150). Values are mean (SEM) (sham, $\mathrm{n}=3 ; 21 \% \mathrm{O}_{2}$, $\mathrm{n}=10 ; 100 \% \mathrm{O}_{2}, \mathrm{n}=10$ ).

$(2.38(0.193) \mathrm{m} / \mathrm{s}$ at baseline $v 2.91(0.130) \mathrm{m} / \mathrm{s}$ at the start of resuscitation) and returned towards baseline values during reoxygenation, but with no differences between the groups $(\mathrm{p}=0.11)$ (fig 1$)$ or between cTnI concentrations $(\mathrm{p}=$ $0.310)$. An inverse relation was found between TR-Vmax and increasing age of the pigs during hypoxaemia $(p=0.034)$.

CO per kg increased during the early phase of hypoxaemia (0.31 (0.02) litres $/ \mathrm{min} / \mathrm{kg}$ at HO $v 0.42(0.02)$ litres $/ \mathrm{min} / \mathrm{kg}$ at H30; $<<0.001$ ), and then decreased slightly (NS) (fig 2). Before resuscitation (R0) there was a difference between the two groups, with a higher mean $\mathrm{CO}$ per $\mathrm{kg}$ in the group resuscitated with $100 \% \mathrm{O}_{2}$. One explanation for this is that pig no 10 in the group receiving room air developed pericardial effusion, severe mitral and aortic valve insufficiency, increasing flow across the ductus arteriosus, and severe tachycardia during the insult, with the heart rate up to 248 beats/min at H30. Then suddenly both heart rate and stroke volume decreased at R0 with a subsequent fall in CO per kg. Further, of the pigs randomised to $100 \% \mathrm{O}_{2}$, pig no 23 had much higher CO per kg because of a high stroke volume ( 3.83 litres $/ \mathrm{min} / \mathrm{kg}$ ) at R0 than any of the other pigs in both groups, and pig no 26 developed arteriovenous block and

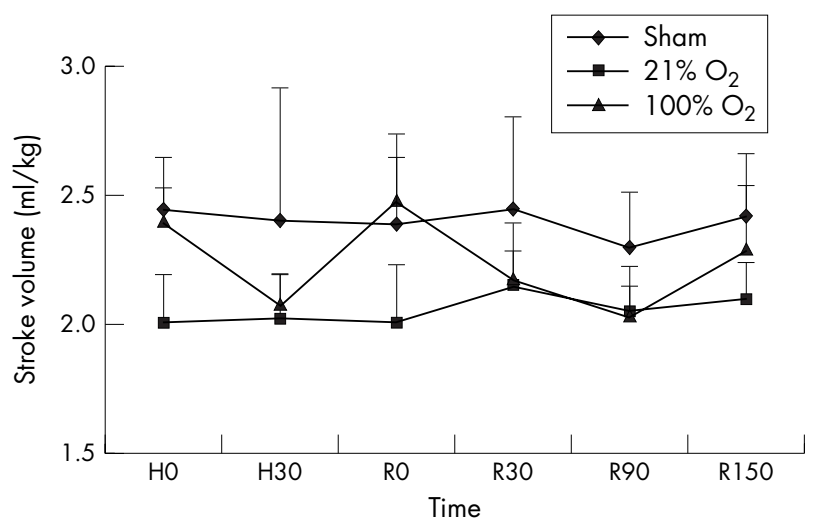

Figure 4 Stroke volume in pigs subjected to hypoxaemia and resuscitated with either $21 \%$ or $100 \% \mathrm{O}_{2}$. Measurements were made at baseline (HO), 30 minutes after the start of hypoxaemia (H30), at the start of reoxygenation (RO), and at 30,90, and 150 minutes of reoxygenation (R30, R90, and R150). Values are mean (SEM) (sham, $\mathrm{n}=3 ; 21 \% \mathrm{O}_{2}, \mathrm{n}=10 ; 100 \% \mathrm{O}_{2}, \mathrm{n}=10$ ). bradyarrhythmia during hypoxaemia, with subsequent severe tachycardia during reoxygenation. During reoxygenation, however, there were no group differences in CO per $\mathrm{kg}$ $(p=0.298)$. The overall changes in CO per $\mathrm{kg}$ were due mainly to changes in heart rate (fig 3 ) and not stroke volume (fig 4).

Adequate recordings of LVP of sufficient quality for further analysis were achieved in only eight pigs. The main problem was that the catheter easily became stuck in the ventricular wall or papillary muscles. LVP decreased during hypoxaemia and returned to normal values during reoxygenation, with no significant differences between the two groups. It changed in the same direction as CO per kg and inversely with TR-Vmax, but this was not significant using regression analysis or area under the curve, except at R150 where we found a relation between LVP max and TR-Vmax $(p=0.032)$.

Electrocardiograms were used to monitor arrhythmias and for Doppler analysis.

\section{DISCUSSION}

cTnI was used as a marker of myocardial injury to assess the difference between baseline and recovery. The increase in cTnI confirmed a severe myocardial injury. As shown previously, there was no protection in the $100 \% \mathrm{O}_{2}$ group during this short period of observation with regard to the amount of cTnI releases. ${ }^{5}$

The pulmonary circulation constricts in response to acute hypoxia, which is reversible on re-exposure to $\mathrm{O}_{2} \cdot{ }^{21}$ Hypoxic pulmonary vasoconstriction is the physiological state in fetal life. Increased $\mathrm{O}_{2}$ at birth is a powerful stimulus inducing vasorelaxation. ${ }^{22}$ The reactivity of the pulmonary vessels to vasoconstrictive stimuli decreases with increasing age. ${ }^{23}$ The pulmonary vessels are especially vulnerable to hypoxic events stimulating vasoconstriction in the first days of life. ${ }^{21} 24$ Accordingly the youngest animals developed the highest PAP in this study.

The main treatment for persistent pulmonary hypertension of the newborn was for many years to correct acidosis, hypoxaemia, and hypercarbia with alkalisation, hyperoxygenation, and induction of hypocarbia. However, hypocarbia has never been shown to reduce mortality or morbidity for this condition. ${ }^{24}$ Hyperventilation with $100 \% \mathrm{O}_{2}$ may actually worsen pulmonary and neurological morbidity. ${ }^{25}$ The stimulus-response relation between graded hypoxaemia and blood flow diversion in the lungs with regard to the hyperoxic part is open to debate. Hyperoxia has been reported to cause pulmonary vasodilatation, ${ }^{26}$ to have no effect on pulmonary vascular resistance, ${ }^{27}$ but also to cause vasoconstriction. ${ }^{28} 29$ In a pig model, hypoxaemia induced pulmonary hypertension and plasma endothelin 1 were as effectively normalised when reoxygenation was performed with room air as with $100 \%$ $\mathrm{O}_{2} \cdot{ }^{30}$ Our study supports this.

Despite a fall in blood pressure, we found an increase in heart rate and CO per $\mathrm{kg}$ in the early phase of hypoxaemia. We can only speculate on the reason for the short period of increased CO per $\mathrm{kg}$ while the systemic blood pressure fell. Neonates regulate their CO mainly by regulating heart rate, ${ }^{31}$ which is consistent with our results. Changes in blood pressure may reflect changes in $\mathrm{CO}$ and/or systemic vascular resistance. A fall in blood pressure will reduce left ventricular afterload and may for a short while improve myocardial performance. CO may be a more sensitive reflection of the haemodynamic situation than blood pressure alone. ${ }^{32}$ Left ventricular output has been suggested to be one of the haemodynamic features most closely linked to outcome in pulmonary hypertension of the newborn. ${ }^{33}$

The subsequent fall observed in $\mathrm{CO}$ per $\mathrm{kg}$ during hypoxaemia is probably caused by increased acidosis and worsening of the cardiac pump function. Low $\mathrm{pH}$ and 
accumulation of lactate may affect the interaction between calcium and troponin in the contractile mechanisms. ${ }^{34}$ An increased PAP will reduce left ventricular preload and lower left ventricular end diastolic volume, contributing to reduced myocardial contractility. We had few pigs with patent ductus arteriosus, and none of them had a pure right-left shunt, which could further have compromised the situation.

After resuscitation, we found an impressive improvement in $\mathrm{CO}$ in both groups. Newborn hearts recover faster than adult hearts after short hypoxaeamic-ischaemic periods. This is probably attributable to higher glycogen stores and less breakdown of high energy phosphate compounds during ischaemic reperfusion injury. ${ }^{35}$ The restoration of CO during reoxygenation was the same in both groups, as well as the cTnI release from the myocardium, showing that $100 \% \mathrm{O}_{2}$ had no protective effect on the myocardium.

LVP changed in the same direction as CO per $\mathrm{kg}$ and inversely with TR-Vmax. Increased PAP will decrease preload to the left ventricle, affect coronary perfusion, and, together with hypoxaemia and acidosis, contribute to increasing left ventricular failure. ${ }^{36}$

Three pigs died from bradyarrhythmia. Hypoxaemia stimulates the carotid body and effectuates reflex responses, involving hyperventilation, peripheral vasoconstriction mediated by $\alpha$ adrenergic sympathetic neurones, and vagally induced bradycardia. ${ }^{37}$ This may lead to profound bradycardia and sinusoidal heart rhythm. ${ }^{38}$ Hypoxia compromises the energetic state of the myocardium and disturbs the ionic balance. $\mathrm{Ca}^{2+}$ and reactive oxygen species play central roles in ischaemic-reperfusion damage possibly by affecting mitochondrial functions, resulting in myocardial cell injury and arrhythmias. $^{39}$

\section{Study limitations}

The pigs were heavily anaesthetised and "instrumented". Even though we allowed a period of recovery and care was taken to minimise myocardial damage, baseline values were probably impaired compared with healthy "non-instrumented" conscious pigs.

Doppler echocardiography as a method has several limitations. The sharp angle of the pig's sternum makes it difficult to obtain exact parasternal long axis views. A small inaccuracy in measuring the diameter of the aortic valve will give rise to big differences in the calculated stroke volume. Angle defaults greater than $0-20^{\circ}$ will also have a large impact on the results. In measuring CO, we actually measure velocity time integrals rather than using volumetric assessments directly. In clinical settings, there is little else to use other than the assessment of CO derived from Doppler measurements.

\section{CONCLUSION}

This study shows that a hypoxic-ischaemic insult affected the myocardium, the conducting system, and the PAP. The youngest animals responded with highest PAP. Reoxygenation with $100 \% \mathrm{O}_{2}$ showed no benefits over the use of ambient air in normalising myocardial function and PAP during this limited time of observation. The important issue may be resuscitation and reoxygenation without hyperoxygenation.

\section{ACKNOWLEDGEMENTS}

This work was supported financially by the Norwegian Council on Cardiovascular Diseases, the Norwegian SIDS Society, the Norwegian Society of Anaesthesiology, and the Laerdal Foundation for Acute Medicine. We thank J C Aasmul, G E Medirad, A Steiro, and L Mørkrid, Department of Clinical Chemistry, for excellent technical assistance. We are also grateful for valuable advice from G Aamodt, Section of Biostatistics, Rikshospitalet University Hospital.

\section{Authors' affiliations}

D Fugelseth, W B Børke, I Matthews, O D Saugstad, Department of Paediatric Research, Rikshospitalet University Hospital, Oslo, Norway W B Børke, K Lenes, I Matthews, E Thaulow, Department of Paediatrics, Rikshospitalet University Hospital

W B Børke, Institute for Surgical Research, Rikshospitalet University Hospital

D Fugelseth, Department of Paediatrics, Ullevål University Hospital, Oslo

Competing interests: none declared

\section{REFERENCES}

1 Ranjit MS. Cardiac abnormalities in birth asphyxia. Indian J Pediatr 2000;67:529-32

2 Hambraeus-Jonzon K, Bindslev L, Mellgård Å, et al. Hypoxic pulmonary vasoconstriction in human lungs. Anesthesiology 1997;86:308-15.

3 Fike CD, Kaplowitz MR. Chronic hypoxia alters nitric-oxide dependent pulmonary vascular responses in lungs of newborn pigs. J Appl Physiol 1996;81:2078-87.

4 Hirsch R, Landt $Y$, Porter S, et al. Cardiac troponin I in pediatrics: normal values and potential use in the assessment of cardiac injury. J Pediatr 1997; 130:872-7.

5 Borke WB, Munkeby BH, Morkrid L, et al. Resuscitation with $100 \% \mathrm{O}_{2}$ does not protect the myocardium in hypoxic newborn piglets. Arch Dis Child Fetal Neonatal Ed 2004;89:F156-60.

6 Fugelseth D, Satas S, Runde M, et al. Cardiac function and morphology studied by two-dimensional Doppler echocardiography in unsedated newborn pigs. Exp Physiol 1999;84:69-78.

7 Fugelseth D, Leach CL, Morin FC, et al. Ductus venosus flow velocity in newborn lambs during increased pulmonary artery pressure. Pediatr Res 2000;47:762-72.

8 Fugelseth D, Satas S, Steen PA, et al. Cardiac output, pulmonary artery pressure, and patent ductus arteriosus during therapeutic cooling after global hypoxia-ischaemia. Arch Dis Child Fetal Neonatal Ed 2003;88:F223-8.

9 World Health Organisation. World health report, Vol 21. Geneva: WHO, 1997.

10 Soll R. Consensus and controversy over resuscitation of the newborn infant. Lancet 1999;354:4-5.

11 Saugstad OD. Is oxygen more toxic than currently believed? Pediatrics 2001;108:1203-5.

12 Niermeyer S, Kattwinkel J, Van Reempts P, et al. International Guidelines for Neonatal Resuscitation: an excerpt from the Guidelines 2000 for Cardiopulmonary Resuscitation and Emergency Cardiovascular Care: International Consensus on Science. Contributors and Reviewers for the Neonatal Resuscitation Guidelines. Pediatrics 2000;106:E29.

13 Saugstad OD, Rootwelt T, Aalen O. Resuscitation of asphyxiated newborn infants with room air or oxygen: an international controlled trial: the Resair 2 study. Pediatrics 1998;102:E1.

14 Saugstad OD, Ramji S, Irani SF, et al. Resuscitation of newborn infants with $21 \%$ or $100 \%$ oxygen, follow-up at 18 and 24 months. Pediatrics 2003; 112:296-300.

15 Vento M, Aseni M, Sastre J, et al. Resuscitation with room air instead of $100 \%$ oxygen prevents oxidative stress in moderately asphyxiated term neonates. Pediatrics 2001;107:642-7.

16 Davis PG, Tan A, O'Donnell CPF, et al. Resuscitation of newborn infants with $100 \%$ oxygen or air: a systematic review and meta-analysis. Lancet 2004;364:1329-33.

17 Hansmann G. Neonatal resuscitation on air: is it time to turn down the oxygen tanks? Lancet 2004;364:1293-4.

18 Saugstad OD, Ramij S, Vento M. Resuscitation of depressed newborn infants with ambient air or pure oxygen: a meta-analysis. Biol Neonate 2005;87:27-34.

19 Skjaerpe T, Hatle L. Diagnosis and assessment of tricuspid regurgitation with Doppler ultrasound. In: Rijsterborgh H, ed. Echocardiology. The Hague: Martinus Nijhoff, 1981:299-304

20 Riggs TW, Rodriguez R, Snider AR, et al. Doppler echocardiographic evaluation of right and left ventricular diastolic function in normal neonates. J Am Coll Cardiol 1989;13:700-5.

21 Raj U, Shimoda L. Oxygen-dependent signaling in pulmonary vascular smooth muscle. Am J Physiol Lung Cell Mol Physiol 2002;283:L671-7.

22 Konduiri GG, Mattei J. Role of oxidative phosphorylation and ATP release in mediating birth-related pulmonary vasodilation in fetal lamb. Am J Physiol Heart Circ Physiol 2002;283:H1600-8.

23 Cornfield DN, Saqueton CB, Porter VA, et al. Voltage-gated $\mathrm{K}(+)$-channel activity in ovine pulmonary vasculature is developmentally regulated. Am J Physiol 2000;278:L1297-304.

24 Steinhorn RH. Persistent pulmonary hypertension of the newborn. Acta Anaesthesiol Scand Suppl 1997; 111:135-40.

25 Bifano $E$, Pfannensteil A. Duration of hyperventilation and outcome in infants with persistent pulmonary hypertension. Pediatrics 1988;81:657-61.

26 Custer JR, Hales CA. Influence of alveolar oxygen on pulmonary vasoconstriction in newborn lambs versus sheep. Am Rev Respir Dis 1985;132:326-31.

27 Robinson SM, Cadwallader JA, et al. Regional alveolar gas composition and lung function in sheep. Respir Physiol 1979;37:239-54.

28 Tate RM, Morris HG, Schroeder WR, et al. Oxygen metabolites stimulate thromboxane production and vasoconstriction in isolated saline-perfused rabbit lungs. J Clin Invest 1984;74:608-13. 
29 Sanderud J, Saugstad OD. Oxygen radicals induce pulmonary vasoconstriction in pigs without activating plasma proteolytic cascade systems. Eur Surg Res 1993;25:137-45.

30 Medbø S, Xiang-Qing YU, Åsberg A, et al. Pulmonary hemodynamics and plasma endothelin-1 during hypoxemia and reoxygenation with room air or 100\% oxygen in a piglet model. Pediatr Res 1998;44:843-9.

31 Friedman WF. The intrinsic properties of the developing heart. Prog Cardiovasc Dis 1972:15:87-111.

32 Kluckow M, Evans N. Relationship between blood pressure and cardiac output in preterm infants requiring mechanical ventilation. J Pediatrics 1996; 129:506-12.

33 Skinner JR, Hunter S, Hey EN. Haemodynamic features at presentation in persistent pulmonary hypertension of the newborn and outcome. Arch Dis Child 1996;74:F26-32.
34 Nakanishi T, Okuda $\mathrm{H}$, Nakazawa $M$, et al. Effect of acidosis on contractile function in the newborn rabbit heart. Pediatr Res 1985;19:482-8.

35 Nakamura $\mathrm{H}$, delNino PJ, Jimenez E, et al. Age related differences in cardiac susceptibility to ischemia/reperfusion injury. J Thorac Cardiovasc Surg 1992:104:165-72.

36 Pepe PE, Raedler C, Lurie KG, et al. Emergency ventilatory management in hemorrhagic states: elemental or detrimental? J Trauma 2003;54:1055-7.

37 Daly MD, Angell-James JE. Role of carotid-body chemoreceptors and their reflex interactions in bradycardia and cardiac arrest. Lancet 1979:1:764-7.

38 Reid MM, Jenkins J, McClure G. Sinusoidal heart rhythms in severe neonatal hypoxia. Arch Dis Child 1979;54:432-5.

39 Sharikabad MN, Hagelin EM, Hagberg IA, et al. Effect of calcium on reactive oxygen species in isolated rat cardiomyocytes during hypoxia and reoxygenation. J Mol Cell Cardiol 2000;32:441-52.

\section{IMAGES IN NEONATAL MEDICINE}

\section{Simple management of isolated proptosis at birth}

A baby was born with proptosis of the right eye at 35 weeks. The baby had required rotation by Keillands forceps, but delivery failed and the baby was delivered by emergency caesarean section after disimpaction of the head from the pelvis. At birth the baby was noted to have a complete proptosis of the right globe and a Keillands forceps mark over the right temporoparietal area but no direct orbital injury (fig 1). Both upper and lower eyelids were retracted exposing the sclera. The pupil of the proptosed eye was mid-sized and unreactive to light. The eye was immediately treated with lubricants and covered with geloperm to prevent exposure keratopathy and corneal ulceration. Spontaneous resolution of eye lid retraction occurred around one hour after birth leading to an appreciable reduction of the proptosis.

Non-contrast computed tomography of the head at 5 hours of age showed mild right eye proptosis with normal optic nerves and retro-orbital space. Oedema settled over five days, and on discharge only pupillary responses remained abnormal. At 4 weeks of age ophthalmic examination was entirely normal.

The likely differential diagnoses in cases such as this are: craniosynostosis; traumatic orbital congestion or retrobulbar bleed from instrumental delivery; or a retro-orbital mass. ${ }^{12}$ However, in the absence of direct orbital injury, we believe that the proptosis in this case was caused by a vacuum effect upon disimpaction of the head. Immediate computed tomography or magnetic resonance imaging after birth is essential to determine the diagnosis and

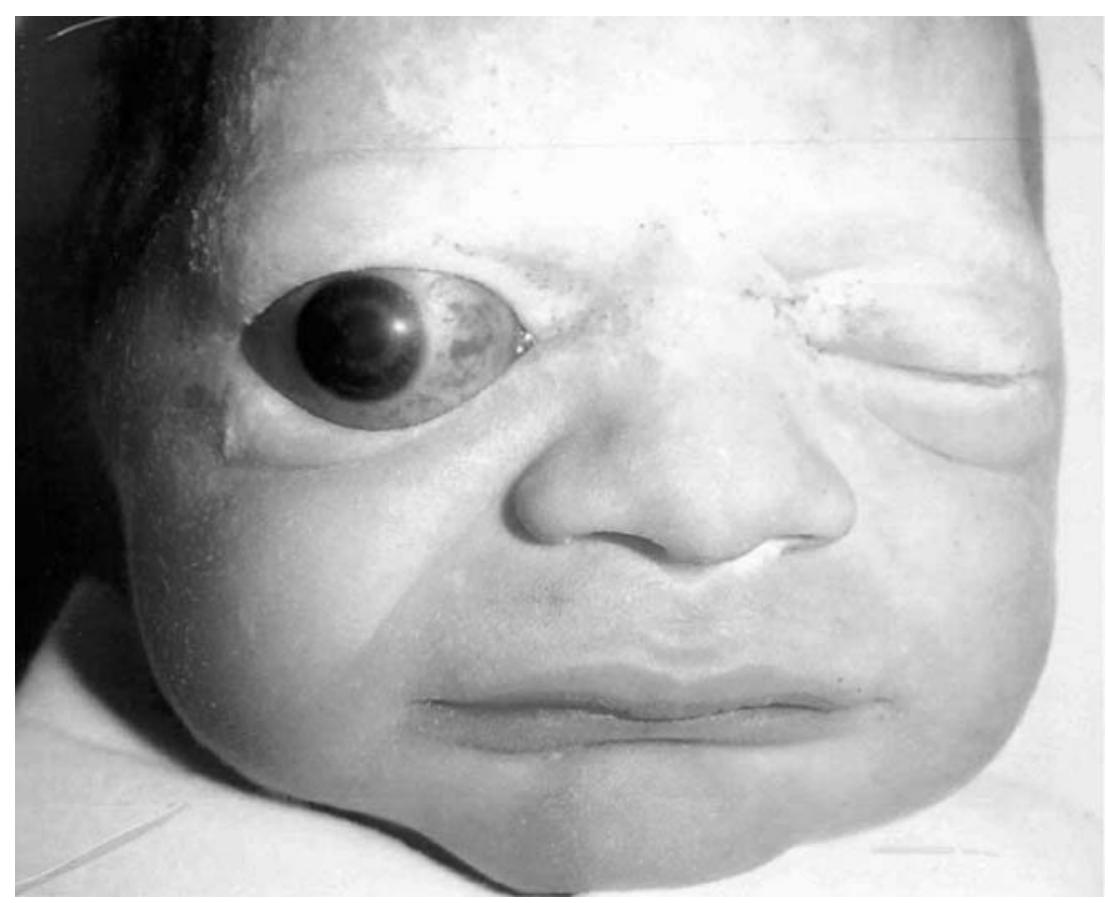

Figure 1 Globe being displaced forward.

treatment required. ${ }^{3-5}$ Simple protective measures and analgesia should be instituted before scanning is carried out.

J M Preece, L Cornette
Peter Congdon Neonatal Unit, Leeds General
Infirmary, Leeds, UK
N El-Hindy
Department of Ophthalmology, Leeds General
Infirmary, Leeds, UK
Correspondence to: Dr Preece, Peter Congdon
Neonatal Unit, Clarendon Wing C floor, Leeds
General Infirmary LS2 9NS, UK;
impreece@doctors.org.uk
Competing interests: none declared

Parental consent was obtained for publication of figure 1

\section{References}

1 Khalil SK, Urso RG, Mintz-Hittner HA. Traumatic optic nerve injury occurring after forceps delivery of a term neonate. J AAPOS 2003;7:146-7.

2 Osmundson, Giangiacomo J. Traumatic optic neuropathology in a newborn. J Pediatr Ophthalmol Strabismus 1999;36:349-50.

3 Robillard BG, Sires BS, Pinczower EF. Optic nerve size in traumatic optic neuropathy. J Craniomaxillofac Trauma 1998:4:13-16.

4 Lee GA, Sullivan TJ, Tsikleas GP, et al. Congenital orbital trauma. Aust N Z J Ophthalmol 1997;25:63-6.

5 Lacey NA, McWilliams S, Jan W, et al. Congenital unilateral proptosis. $\mathrm{Br} J$ Radiol 2002;75:191-2. 